https://helda.helsinki.fi

Gene-environment correlations in parental emotional warmth and intolerance : genome-wide analysis over two generations of the Young Finns Study

Dobewall, Henrik

2019-03

Dobewall , H, Savelieva , K, Seppälä , I , Knafo-Noam , A , Hakulinen , C , Elovainio , M , Keltikangas-Jarvinen , L , Pulkki-Råback , L , Raitakari , O T , Lehtimäki , T \& Hintsanen , M 2019 , ' Gene-environment correlations in parental emotional warmth and intolerance : genome-wide analysis over two generations of the Young Finns Study ' , Journal of Child Psychology \& Psychiatry , vol. 60 , no. 3 , pp. 277-285 . https://doi.org/10.1111/jcpp.12995

http://hdl.handle.net/10138/324793

https://doi.org/10.1111/jcpp.12995

acceptedVersion

Downloaded from Helda, University of Helsinki institutional repository.

This is an electronic reprint of the original article.

This reprint may differ from the original in pagination and typographic detail.

Please cite the original version. 
Title: Gene-environment correlations in parental emotional warmth and intolerance:

Genome-wide analysis over two generations of the Young Finns Study

\author{
Henrik Dobewall ${ }^{1,6}$, Kateryna Savelieva ${ }^{1}$, Ilkka Seppälä ${ }^{2}$ Ariel Knafo-Noam ${ }^{3}$, Christian \\ Hakulinen $^{1}$, Marko Elovainio ${ }^{1}$, Liisa Keltikangas-Järvinen ${ }^{1}$, Laura Pulkki-Råback ${ }^{1}$, Olli T. \\ Raitakari ${ }^{4}$, Terho Lehtimäki ${ }^{2, \#}$, and Mirka Hintsanen, ${ }^{5, \#, *}$
}

${ }^{1}$ Department of Psychology and Logopedics, Faculty of Medicine, University of Helsinki, Helsinki,

Finland

${ }^{2}$ Department of Clinical Chemistry, Fimlab Laboratories, Faculty of Medicine and Life Sciences, University of Tampere, Tampere, Finland.

${ }^{3}$ Department of Psychology, Hebrew University of Jerusalem, Jerusalem, Israel

${ }^{4}$ Research Collegium for Applied and Preventive Cardiovascular Medicine, University of Turku, Turku, Finland

${ }^{5}$ Unit of Psychology, University of Oulu, Oulu, Finland

${ }^{6}$ Faculty of Social Sciences, Health Sciences, University of Tampere, Tampere, Finland

\# The authors contributed equally.

* Correspondence concerning this article should be addressed to Professor Mirka Hintsanen, University of Oulu, P.O.Box 2000 (Yliopistokatu 9), 90014 University of Oulu, Finland. E-mail: mirka.hintsanen@oulu.fi. 


\begin{abstract}
Background: Genomic analysis of the child might offer a new potential to illuminate human parenting. We examined whether offspring $(\mathrm{G} 2)$ genome-wide genotype variation (SNPs) is associated with their mother's (G1) emotional warmth and intolerance, indicating a geneenvironment correlation. If this association is stronger than between G2's genes and their emotional warmth and intolerance towards their own children, then this would indicate the presence of an evocative gene-environment correlation. To further understand how G1 mother's parenting has been evoked by genetically influenced characteristics of the child (G2), we examined whether child (G2) temperament partially accounted for the association between offspring genes and parental responses.
\end{abstract}

Methods: Participants were from the Young Finns Study. G1 mothers (N=2349; mean age 39 years) self-reported the emotional warmth and intolerance towards G2 in 1980 when the participants were from 3 to 18 years old. G2 participants answered the same parenting scales in $2007 / 2012(\mathrm{~N}=1378$; mean age $=38$ years in $2007 ; 59 \%$ female $)$ when their children were on average 11 years old. Offspring temperament traits were self-reported in 1992 (G2 age range 15 to 30 years). Estimation of the phenotypic variance explained by the SNPs of G2 was done by genome-wide complex trait analysis with restricted maximum likelihood (GCTA-GREML). Results: Results showed that the SNPs of a child (G2) explained $22.6 \%$ of the phenotypic variance of maternal intolerance $(\mathrm{G} 1$; p-value=.039). G2 temperament trait negative emotionality explained only 2.4 percentage points of this association. G2 genes did not explain G1 emotional warmth or G2's own emotional warmth and intolerance. However, further analyses of a combined measure of both G1 parenting scales found genetic effects. Parent or child gender did not moderate the observed associations.

Conclusions: Presented genome-wide evidence is pointing to the important role a child plays in 
affecting and shaping his/her family environment, though the underlying mechanisms remain unclear.

Key words: Parenting; molecular genetics; child development; temperament; evocative geneenvironment correlation; children's' genome-wide genotype variation; GCTA-GREML. 


\section{Gene-environment correlations in parental emotional warmth and intolerance: Genome-wide analysis over two generations of the Young Finns Study}

\section{Introduction}

\subsection{Gene-environment correlations}

The developmental literature often focuses on parental effects on their children. There is a consensus that parents influence their children's psychological development, and these effects have been shown to exist independently of shared genes between the parent and the child (Stams, Juffer, \& van IJzendoorn, 2002). Also, parental behavior has multiple determinants, among which the characteristic of the child influencing parenting have received considerable attention (Belsky, 1984). For instance, if a parent perceives child-rearing as burdensome may be induced by the child's difficult temperaments. Children, therefore, are not just passive receivers of parenting because children evoke differential responses in the parents, who react to their children's characteristics. This leads to gene-environment correlations (rGE), that is, "the phenomenon in which children's genetically influenced characteristics are correlated with the behavior or responses of the environment" (Avinun \& Knafo, 2014, p.87).

In the current study, we were interested in the association between children's genes and the parenting they have received to elucidate the children's influences on their family environment. It has been suggested that normal variation in parental responses might be evoked by genetically influenced characteristics of a child (e.g., temperament traits) (Avinun \& Knafo, 2014; Belsky, 1984; Kendler, 1996; Klahr \& Burt, 2014). In this case, the condition for what is called a reactive or evocative rGE is fulfilled. If evocative rGEs are at play, then the genes of children should be associated with the responses of the parent more than the parents' genes (Pener-Tessler et al., 2013). There is also an alternative explanation for an observed association between genetic variation and environmental exposure that needs to be considered, namely, passive rGE. Passive 
rGE occurs because parents give their children not only genes but also an environment, which itself is influenced by shared genes (Plomin, DeFries, \& Loehlin, 1977). A third type, active rGE, arise if an individual selects his or her environment based on genetic tendencies (Plomin et al., 1977). Active rGE, however, does not apply to the context of parenting because children neither choose their parents nor can they avoid their reactions.

\subsection{Previous studies}

Only recently, studies have started to systematically disentangle passive rGEs from evocative rGEs in the context of parenting (Neiderhiser et al., 2004). A number of candidate gene studies have assessed whether parenting is evoked as a reaction to children's genetically influenced characteristics. These studies first examined the effect of offspring variation in one or more polymorphisms, for example, in dopamine (Hayden et al., 2010, 2013; Lucht et al., 2006; MillsKoonce et al., 2007), oxytocin (Kryski et al., 2014), and serotonin (Kopala-Sibley et al., 2016) pathway genes on parenting. Then, some of these studies have examined whether the child's temperament can explain the effect of these candidate genes on parenting. Temperament is defined as early-emerging behavioral dispositions, that is largely heritable (Buss, 1991; Saudino, 2005; Shiner et al., 2012). Although temperament is comparatively stable, this stability varies substantially depending on the developmental stage examined, in that it shows relatively lower stability in early childhood compared to, for example, late adolescence or early adulthood (Roberts \& DelVecchio, 2000). And, indeed, characteristics of the children, such as self-control (PenerTessler et al., 2013), negativity and affectivity (Hayden et al., 2013; Kryski et al., 2014; MillsKoonce et al., 2007), or broader sets of temperament dimensions (Lucht et al., 2006) mediated, at least partially, the genetic influences. Two of these studies were further able to rule out the possibility of passive rGE by controlling for the same candidate genes in parents and showing that shared genes did not fully account for the effect of studied temperament traits (Mills-Koonce et al., 
2007; Pener-Tessler et al., 2013). Further evidence for evocative rGE was added by adoption studies (e.g., Ge et al., 1996). Finally, two recent meta-analytic reviews of children-as-twins studies have found cumulative evidence for evocative rGE (Avinun \& Knafo, 2014; Klahr \& Burt, 2014), resulting in heritability estimates in the range of 23 to $40 \%$ of the variance for parental positivity (including control) and negativity. The exact strength of the correlation between genetically influenced characteristics of children and the parenting they experience, however, is still uncertain due to the sometimes problematic assumptions of twin studies, while candidate gene studies are limited to examining a narrow range of genes and often have the limitation that they do not replicate in other samples. An increasing number of studies have used genes of children to explain a phenotype in their parents (Joshi et al., 2016; Marioni et al., 2016), and molecular genetic evidence is needed to estimate the proportion of the variance the rGEs explain of the parental responses. This can be done by utilizing genome-wide complex trait analysis with restricted maximum likelihood (GCTA-GREML) (Yang et al., 2011; Yang et al., 2016), indicating whether two unrelated individuals are more similar in the parenting they experience because they share the same genes.

\subsection{The current study}

In the current study, we used parents' self-reports of their emotional warmth and intolerance towards their children in two Finnish generations - parent generation (G1) and offspring generation (G2) - obtained at a similar age and developmental stages. Emotional warmth and intolerance are an expression of the relationship between parents and children, which define the overall emotional atmosphere within a family and thereby reflect parenting qualities (Dix, 1991). A positive family

environment, first of all, includes connectedness and love between parent and child (operationalized as emotional warmth in our study) (Avinun \& Knafo-Noam, 2017; Maccoby, 1980; MacDonald, 1992). Another related aspect of parenting is the lack of parents' acceptance and responsiveness towards the feelings, opinions, and behavior of the child (Maccoby, 1980). Therefore, we also used 
a measure of parental intolerance towards their children's normal activity. The current study applied these two aspects of parenting separately, as well as combined them into an overall measure of the emotional atmosphere within the family.

We follow a three-step approach to examine the strength of (evocative) rGEs in parental emotional warmth and intolerance. The first aim is to examine whether the child's genes are associated with the parenting they have received (step 1). Thus, we estimated the percentage the Single Nucleotide Polymorphisms (SNPs) of G2 explain in the phenotypic variance of G1 emotional warmth and intolerance. This rGE estimate will serve as a comparison standard for the heritability estimate obtained in the children-as-twins studies (Avinun \& Knafo, 2014; Klahr \& Burt, 2014).

The second aim is to understand better how the children affect and shape their family environment. For a rGE to be evocative, it has to work somehow through the genetically influenced characteristics of the child (Saudino, 2005). Therefore, we tested whether the temperament of the offspring is responsible for the association between G2 genes and G1 parenting (step 2). We do so by controlling for G2 temperament trait of negative emotionality, which is expected to reduce the variance explained by G2 genes in G1 parental emotional warmth and intolerance. Negative emotionality (defined as distress that is accompanied by intense autonomic arousal) is a good candidate, compared to other temperament traits, because parents might change their responses to children most who are high on difficult temperaments (Belsky, 1984; Buss, 1991), and it has been shown to be involved in other rGEs (Hasenfratz et al., 2015; Hayden et al., 2013; Kryski et al., 2014; Mills-Koonce et al., 2007).

The third aim is to examine the heritability estimate of G2 parental emotional warmth and intolerance towards their own children based on their (G2) own genes. Even though it is interesting in its own right whether individuals' genes are associated with the emotional warmth and intolerance they express towards their children; this analysis also allows to find out whether the 
heritability estimate of $\mathrm{G} 2$ parenting is lower than the rGE estimate obtained for G1 parenting. If this is the case, then it is likely that evocative rGE rather than passive rGE account for the responses children experience in terms of parenting. It is further possible that the strength of the (evocative) rGE is moderated by the parent or child gender (Avinun \& Knafo-Noam, 2017; Avinun \& Knafo, 2014). Because boys and girls might receive different parenting and because mothers and fathers might express differential parenting qualities, we test the interactions between G2 gender and G2's genome-wide genotype variation in explaining emotional warmth and intolerance.

\section{Materials and methods}

\subsection{Setting and ethical considerations}

The current study uses data from the multidisciplinary, prospective Young Finns Study (YFS) (Akerblom et al., 1991; Raitakari et al., 2008), which is representative of the Finnish population. The YFS was conducted in Helsinki, Kuopio, Oulu, Tampere, and Turku and the regions surrounding these cities. The YFS complies with the Helsinki Declaration, and local ethics committees approved the study. Follow-ups were approved by the ethics committee at the University of Turku. All participants provided written informed consent. For a more detailed description of the procedure of the YFS, the reader is referred to Raitakari and colleagues (2008).

The first study wave of the YFS was conducted in 1980, in which G1 answered the psychological questionnaire including questions about the emotional warmth and intolerance towards their children (G2 age was 3, 6, 9, 12, 15, and 18 years, respectively). In 1992, G2 selfreported on their temperament traits for the initial time (G2 age range 15-30 years). In 2007, G2 reported on their emotional warmth and intolerance towards their own children. Those G2 participants who did not yet have children in 2007 reported about their parenting in 2011/2012. In the case responses were given in both study waves, we gave priority to the first assessment in 2007 . Parenting was assessed using the same questionnaire and scales in both generations. In G1, the 
mothers of $\mathrm{G} 2$ reported their emotional warmth and intolerance, and in G2 either mothers (59\%) or fathers $(41 \%)$ reported emotional warmth and intolerance towards their own children. Moreover, the assessment was conducted at approximately the same developmental stages in both generations (G1 mean age in $1980=39$ years, and G2 mean age in 2007=38 years). Figure 1 presents our study design and timeline.

The initial YFS sample consisted of 3596 Finnish children and adolescents (G2) and their mothers (G1). We excluded parent-child pairs if they had missing information on parenting and used data of those G2 participants who agreed to be genotyped ( $N$ varied from 1378 to 2349 depending on the research question).

\section{Insert Figure 1 about here}

\subsection{Measures}

\section{Parental emotional warmth and intolerance}

Parenting was operationalized with the parent's self-reported emotional warmth and intolerance towards the child. These scales were derived from the Operation Family Study (Makkonen et al., 1981). Four items assessed emotional warmth: "I enjoy spending time with my child"; "I am important to my child"; "My child is important to me"; and "My child enables me to self-actualize myself." Intolerance was measured with three items: "In difficult situations, the child is a burden"; "I often become irritated with my child"; and "My child takes too much of my time." All items were scored on a 5-point Likert-type scale, ranging from "never or almost never" to "always or almost always," and then averaged to form two variables - emotional warmth and intolerance. These two aspects of parenting were examined separately because they are conceptually different (Savelieva, Keltikangas-Järvinen et al., 2017; Knafo \& Plomin, 2006; Savelieva, Pulkki-Råback et al., 2017), and have shown distinct criterion validity (Gluschkoff et al., 2017; Hintsanen et al., 2010). Reliability for the emotional warmth (Cronbach's alphas were 0.68 for G1 in 1980; 0.72 for G2 in 2007, 0.69 in 2012) and intolerance (0.67 for G1 in 1980; 0.71 for G2 in 2007 and 2012) 
scales was acceptable. Because offspring (G2) age ranged from 3 to 18 years when G1 emotional warmth and intolerance were assessed, we standardized the parenting scales within each age cohort of G2 to compensate for this age difference. The same procedure was applied for G2 emotional warmth and intolerance within the age cohorts G2's children, as their age ranged from 1 to 30 years during the assessment (Savelieva, Pulkki-Råback, et al., 2017). At the same time, the emotional warmth and intolerance scales are correlated (see Table S1) and might be aspects of a broader parenting quality that reflects on the overall emotional atmosphere within a family. Thus, we also combined the items of these two scales to a single measure (i.e., the higher values indicate warmer and more tolerant parental responses).

\section{Negative emotionality}

The Buss-Plomin EAS temperament model was used to assess negative emotionality (Buss, 1991). It was assessed in 1992 with 12 items, e.g., "I am easily frightened." G2 self-rated their temperament on a 5-point scale, ranging from "totally disagree" to "totally agree." Reliability of temperamental negative emotionality was high (Cronbach's alpha was 0.82 ).

\subsection{Genotyping}

The genome-wide analyses of the YFS G2 were performed using the Illumina 670k genotyping array (Smith et al., 2010). Imputation was done utilizing the IMPUTE2 software (Howie, Donnelly, \& Marchini, 2009) with the 1000 Genomes Project March 2012 haplotypes as a reference. Results indicate an excellent imputation quality (info 0.99). G1 did not undergo genotyping.

\subsection{Statistical analysis}

We prepared the genetic relationship matrix (GRM) of the G2 participants in the genome-wide complex trait analysis (GCTA) program (Yang et al., 2011). Estimation of the phenotypic variance 
explained by the SNPs $\left(\mathrm{h}^{2}\right)$ was done by employing restricted maximum likelihood (GREML). Even though this method has recently been criticized et al., 2015), GCTA-GREML is generally seen as producing reliable and stable estimates of heritability (Realo et al., 2017; Vattikuti et al., 2012; Yang et al., 2016). The logic of GCTA-GREML is that the extent to which phenotypic similarity between genetically-unrelated individuals is associated with the degree of similarity in DNA markers indicates the heritability of the phenotype. We ran a sequence of GCTA-GREML analyses to explain the phenotypic variance in parenting by the G2 SNPs. The GCTA-GREML program does not include a feature for conducting mediation analyses. It is possible, however, to adjust $\mathrm{h}^{2}$ for G2 temperament traits. This is similar to Barron and Kenny's (1986) classic approach to test for mediation. Finally, to test whether the G2 gender moderates a particular (evocative) rGE we added a gene-environment interaction with the option reml-lrt 2 to our models. These analyses allow determining the significance of the variance of gender-specific genetic effects.

Power analysis (http://cnsgenomics.com/shiny/gctaPower/) (Visscher et al., 2014) revealed a $40 \%$ chance of detecting an SNP based rGE estimate of 0.23 in G1. The chance to detect a heritability estimate with the same size of G2 was remarkably smaller (17\%).

\subsection{Preliminary analysis}

Attrition analysis showed that those G2 individuals who had dropped out (i.e., those G2 who did not have data either on their own or their mothers' ratings of parenting quality and who were not genotyped) were younger (mean age in 1980: 10.1 vs. 10.9, $\mathrm{p}<.001$ ) and more likely to be male (55 vs. $40 \%, \mathrm{p}<.001)$ compared to the $\mathrm{G} 2$ participants from the analytical sample. The excluded participants had experienced higher intolerance in childhood according to their mother's ratings compared to the included (mean score: 2.12 vs. $1.99, \mathrm{p}<.001$ ). There were no other differences in experienced emotional warmth or self-reported temperament (all p-values>.114).

Inter-correlations of the main study variables are presented in Table S1 (Online Appendix). 


\section{Results of the GCTA - GREML analysis}

As shown in Table 1, the SNP-based gene-environment correlation $\left(h^{2}\right)$ indicated that $22.6 \%$ of the phenotypic variance of maternal intolerance in G1 was explained by genes of G2 ( $\mathrm{p}=.039)$. Maternal emotional warmth was not significantly associated with offspring genes $\left(h^{2}=0.09\right.$, $\mathrm{p}=.243$ ). The effect of offspring genes on parents' overall responses (i.e., mother's tolerance and emotional warmth combined) was $21.4 \%(\mathrm{p}=.048)$. These analyses (step 1) were adjusted for $\mathrm{G} 2$ age and gender, and four genetic principal components to take into account any possible population stratification (Price et al., 2006; Realo et al., 2017).

In the second step, we additionally controlled for the G2 temperament trait of negative emotionality. Results indicated that the phenotypic variance of maternal intolerance was reduced only by 2.4 percentage points from $22.6 \%$ to $20.2 \%$ ( $\mathrm{p}=.121)$. Accounting for temperamental emotional negativity in the combined parenting measure explained 5.3 percentage points of the association, reducing it to $16.1 \%(\mathrm{p}=.167)$. The rGE estimates $\mathrm{h}^{2}$, however, became non-significant.

The SNPs of G2 explained $20.2 \%$ in emotional warmth of G2 (p=.150) and $0.0 \%$ in intolerance ( $\mathrm{p}=.500)$ (step 3). The heritability estimates were not significant, however. Also, the combined parenting scale of G2 was not significantly associated with their own genes $\left(h^{2}=0.06\right.$, $\mathrm{p}=.381$ ). In this step, we used G2 gender, gender and age of G2's first child, and the first four genetic principal components as covariates.

Finally, we added to each of our models an interaction term between G2 gender and their genes. These analyses did not indicate any differences between boys and girls (steps 1 and 2) or between mothers and fathers (step 3) because none of the gender-specific genetic effects were statistically significant (e.g., for G1 intolerance in step 1 the p-value was .320).

In combination, steps 1-3 of our approach showed that there was an association between offspring genes on parents' responses (i.e., mother's intolerance and the combined parenting 
measure) - indicating the presence of a $\mathrm{rGE}$ - , which was largely robust to adding the temperament trait negative emotionality into the model. This significant rGE cannot be explained by cultural variables because in the analyses we were controlling for population stratification. Finally, as offspring's own parenting was not correlated with their genes, passive rGE might not have caused the observed genetic association. G2 gender did not moderate the observed associations.

\section{Insert Table 1 about here}

\section{Sensitivity analysis}

To test the robustness of our findings we have conducted some further analyses.

We repeated the first step for the seven single items. Child's genes explained the variance significantly in the emotional warmth item "I enjoy spending time with my child" $\left(h^{2}=0.213\right.$, $\mathrm{p}=.043)$ and in the intolerance item "I often become irritated with my child" $\left(h^{2}=0.224, \mathrm{p}=.037\right)$. The other items were not significantly associated, namely, "My child is important to me" $\left(h^{2}=0.147\right.$, $\mathrm{p}=.108)$, "I am important to my child" $\left(h^{2}=0.076, \mathrm{p}=.276\right)$, "My child enables me to self-actualize myself" $\left(h^{2}=0.000, \mathrm{p}=.500\right)$, "In difficult situations, the child is a burden" $\left(h^{2}=0.201, \mathrm{p}=.053\right)$, and "My child takes too much of my time" $\left(h^{2}=0.000, \mathrm{p}=.500\right)$. Thus, we found in the single item analyses genetic effects for both aspects of parenting, suggesting that the formulation of the items influenced the strength of the observed genetic associations.

We have repeated the second step by controlling for all three temperament types of the EAS theory (Buss, 1991). The EAS types form a full temperament theory, and they are by definition broad and thus cover much of the genetically influenced child characteristics. Accounting additionally for temperamental activity and sociability reduced the variance explained in maternal intolerance from $22.6 \%$ ( $\mathrm{p}=.039)$ to $19.6 \%(\mathrm{p}=.127)$, for instance. The strength of the remaining genetic effect is consequently similar to the $20.2 \%(\mathrm{p}=.121)$ when adjusting for negative emotionality only. 


\section{Discussion}

To our knowledge, the current study is the first of its kind to provide genome-wide evidence for the role of children's genotype in the parenting they have received, in terms of emotional warmth and intolerance. The most important result of the current study is that the SNPs of a child explain about $23 \%$ of the phenotypic variance of maternal intolerance, significant at $\mathrm{p}<.05$ level. These types of relations between genes and the environment are referred to as gene-environment correlations. This estimate is similar to the heritability of parental positivity and negativity obtained in two recent meta-analyses of children-as-twins studies (Avinun \& Knafo, 2014; Klahr \& Burt, 2014). Note that genetic effects are not all SNP based. Thus, the total genetic effect might be larger than estimated by the current GCTA-GREML analysis.

We found that offspring generation genes are associated with intolerance but not with emotional warmth in the generation of their parents. While emotional warmth asserts the love and connectedness expressed within a family, high intolerance measures parental perceptions of the child as demanding and, in some situations, even as burdensome. In line with this finding, the metaanalysis of children-as-twins studies by Avinun and Knafo (2014) has found that parental negativity was more strongly associated with offspring genes than with parental positivity. Our findings might, therefore, partially be explained by the circumstance that intolerance captures not only parents' low acceptance and responsiveness towards the child but also their negative child-rearing experiences, whereas warmth is more of a positive approach to the child and is less conditional upon the child's (negative) behaviors (Knafo \& Plomin, 2006). It should, however, be noted that in analyses with the combined parenting measure and further analyses of the single items of both aspects of parenting we found genetic effects. This pattern indicates that the emotional warmth and intolerance, while 
being conceptually different, empirically might belong to a broader parenting quality which has a joint origin in the genetic makeup of the offspring.

Children that differ in their genetically influenced temperament (negative emotionality) elicit certain responses from the social environment (parenting) (Avinun \& Knafo, 2014; Klahr \& Burt, 2014; Plomin et al., 1977). Temperament development should therefore not be seen as unidirectionally affected by environmental factors, but rather in a way that children initially differ in their temperament which then affects and shapes social interaction with their parents and, thus, changes the child's environment (Belsky, 1984, Buss, 1991; Sanson, Hemphill, \& Smart, 2004). Overall, we found only weak support for the rGE to be evocative rather than passive, because controlling for G2 temperament did not reduce the variance explained by G2 genes in G1 parental intolerance notably. There are, however, many genetically influenced child characteristics, such as their self-control (Pener-Tessler et al., 2013), which may have evoked the parental responses. Thus, our main results should be interpreted in the light of the fact that temperament was assessed in G2 only with a single trait. Our further analyses showed that adjusting the rGE estimates for all three traits of the EAS theory did not notably increase the amount of variance accounted for by child's temperament. G2 temperament was assessed many years after G1 reported on the maternal emotional warmth and intolerance, which is especially problematic because the stability of temperament is lower in early childhood (Roberts \& DelVecchio, 2000). Thus, our measure can be seen merely as an approximation of the temperament at the time of G1 parenting was assessed. Hasenfratz and colleagues (2015), for example, have found heritability of peer problems and showed that temperament traits were partially responsible for this rGE. This line of research illustrates — as intended by our 3-step approach — that evocative rGE has to work through the genetically influenced characteristics of a child (Avinun \& Knafo, 2014; Kendler, 1996; Klahr \& Burt, 2014). 
We also tested whether child and parent gender moderated the strength of (evocative) rGE. Whereas the previous literature on gender effects is somewhat inconclusive (Avinun \& KnafoNoam, 2017; Avinun \& Knafo, 2014), the current study did not find any significant interaction between G2 gender and G2 genes in explaining the variance in parenting.

Children-as-twins studies exclude by design the possibility that results were confounded by passive rGE (Avinun \& Knafo, 2014; Klahr \& Burt, 2014). We found that G2 genes better explain G1 parenting than they explain G2 parenting towards their own children. This is in line with a study by Neiderhiser and colleagues (2004), combining children-as-twins and children-of twins designs, which found that passive rGE accounted for mother's positivity and monitoring, while nonpassive/evocative rGE had caused mother's negativity and control. In the current study, the effect of G2 genes on G2 parenting might have also been too small for detection due to the smaller $N$ of this analysis (step 3). If the observed correlation between G2 genes and G1 parenting would indeed be due to passive rGE, then this would indicate a significant role of genetic variation shared by mothers and their children in parenting. There is further another reasonable explanation for the lack of associations between G2 parenting and G2 genes. It is likely that the parenting of G2 itself is evoked by the characteristics of their own children. For example, it has been shown that parents of two or more children respond differently to their feelings, opinions, and behavior (Jenkins, McGowan, \& Knafo-Noam, 2016).

On the one hand, parents serve as role models and want to pass on to their children certain values, including what they think is good parenting. On the other hand, that G2 genes are stronger associated with G1 parenting than with G2's own parenting might also explain the only rather modest transmission of parental emotional warmth and intolerance from the one generation to the next generation found in the literature (Savelieva, Keltikangas-Järvinen, et al., 2017; Savelieva, Pulkki-Råback, et al., 2017). 


\section{Limitations and Strengths}

The current study has some limitations. While being large for dyadic data, the current sample size is at the lower end of what is desirable in molecular genetic studies. That the analyses were underpowered increases the risk of false negative findings (i.e., that significant genetic effects were not detected) and limits the scope and interpretability of our results. However, to our best knowledge, the YFS is the only genetically informed study assessing parenting at a similar age and developmental stage in two generations. Future work could combine available data sets in which information on both parents' genes and parenting and young children's genes and temperament are available to replicate our results conceptually. Another limitation is that parenting was assessed with a non-standard self-report measure rather than observations. Attrition analysis suggested that individuals who dropped out, additional to being younger and more often male, were more likely to experience lower levels of maternal intolerance, which limits the generalizability of our results. With less attrition and more variation in parental responses one would expect an increase in the phenotypic variance explained by genes. Also the relatively low reliability of the used parenting scales (<.75) indicates that measurement error may have had a negative influence on the ability of our analyses to detect stronger genetic effects. To continue, the GCTA-GREML program does not include a feature for conducting mediation analyses. We nonetheless wanted to assess whether the effect of children's genes on the parenting they have received was (partially) explained by their temperament. Step 2 of our main analyses that controls for variation in child's temperament is closest to Barron and Kenny's (1986) classic approach to test for mediation. This approach, however, tends to produce false negative findings. The developer of the GCTA-GREML program should try to integrate less conservative and more powerful approaches, such as, the non-parametric 
bootstrapping method or Monte Carlo simulation, that would allow producing confidence intervals for an indirect effect.

The current study also has several notable strengths. We reported results based on population-based, prospective data of two generations, using the same questions to assess parenting in both generations. The temperament dimension of negative emotionality was assessed in offspring by a well-validated measure, 12 years after (G1) and 15 years before (G2) parenting was assessed. The evocative rGE estimate, therefore, is not confounded by common rater variance.

\section{Conclusions}

The current study showed that genome-wide complex trait analysis with restricted maximum likelihood could be used to estimate the variance in parenting which can be explained by the Single Nucleotide Polymorphisms of their children. The fact that two unrelated individuals are more similar in the parenting they have experienced during childhood, compared to those who do not happen to share genes, provides a very robust test of genetic causality and does not necessitate the assumptions of twin studies. Our results are the first genome-wide molecular genetic evidence on rGE and confirm previous behavior genetic (i.e., twin) studies pointing to the important role a child plays in affecting and shaping his/her family environment. These findings on rGE are promising and require replication. Future work should identify those genetically influenced characteristics of the child that evoke the differential parenting in the parents. 


\section{Key points:}

- It is known that children's genetically influenced characteristics are correlated with the responses of their parents in terms of parenting.

- Genes of children explained their parents' intolerance but not emotional warmth, and their temperament was tested as a potential intervening variable of this association.

- $\quad$ Parents' own genes were not significantly associated with their parenting.

- $\quad$ Our results stress that children have an important role in affecting and shaping their family environment.

- The current study is the first of its kind to provide genome-wide evidence for the role of children's genotype in the parenting they have received. 


\section{References}

Akerblom, H. K., Uhari, M., Pesonen, E., Dahl, M., ... Kannas, L. (1991). Cardiovascular risk in young Finns. Annals of Medicine, 23(1), 35-39. https://doi.org/10.3109/07853899109147928

Avinun, R., \& Knafo-Noam, A. (2017). Parental brain-derived neurotrophic factor genotype, child prosociality, and their interaction as predictors of parents' warmth. Brain and Behavior, 7(5), e00685. https://doi.org/10.1002/brb3.685

Avinun, R., \& Knafo, A. (2014). Parenting as a reaction evoked by children's genotype. Personality and Social Psychology Review, 18(1), 87-102. https://doi.org/10.1177/1088868313498308

Baron, R.M., \& Kenny, D.A. (1986). The moderator-mediator variable distinction in social psychological research: Conceptual, strategic, and statistical considerations, Journal of Personality and Social Psychology, 51(6), 1173-1182. https://doi.org/10.1037//00223514.51.6.1173

Belsky, J. (1984). The determinants of parenting: A process model. Child Development, 55, 83-96. https://doi.org/10.2307/1129836

Buss, A. (1991). The EAS theory of temperament. Explorations in Temperament: International Perspectives on Theory and Measurement. https://doi.org/10.1007/978-1-4899-0643-4\{_\}4

Dix, T. (1991). The affective organization of parenting: Adaptive and maladaptive processes. Psychological Bulletin, 110(1), 3-25. https://doi.org/10.1037/0033-2909.110.1.3

Ge, X., Conger, R.D., Cadoret, R.J., Neiderhiser, J.M., Yates, W., Troughton, E., \& Stewart, M.A. (1996). The developmental interface between nature and nurture: A mutual influence model of child antisocial behavior and parent behaviors. Developmental Psychology, 32(4), 574-589. https://doi.org/10.1037/0012-1649.32.4.574

Gluschkoff, K., Keltikangas-Järvinen, L., Pulkki-Råback, L., Jokela, M., ... Hintsanen, M. (2017). Hostile parenting, parental psychopathology, and depressive symptoms in the offspring: A 32year follow-up in the Young Finns Study. Journal of Affective Disorders, 208, 436-442.

Hasenfratz, L., Benish-Weisman, M., Steinberg, T., \& Knafo-Noam, A. (2015). Temperament and peer problems from early to middle childhood: Gene-environment correlations with negative emotionality and sociability. Development and Psychopathology, 27(4pt1), 1089-1109. https://doi.org/10.1017/S095457941500070X

Hayden, E.P., Hanna, B., Sheikh, H.I., Laptook, R.S., Kim, J., Singh, S.M., \& Klein, D.N. (2013). Child dopamine active transporter 1 genotype and parenting: Evidence for evocative geneenvironment correlations. Development and Psychopathology 25, 163-173. https://doi.org/10.1017/S0954579412000971

Hayden, E.P., Klein, D.N., Dougherty, L.R., Olino, T.M., ... Singh, S.M. (2010). The dopamine D2 
receptor gene and depressive and anxious symptoms in childhood: Associations and evidence for gene-environment correlation and gene-environment interaction. Psychiatric Genetics, 20(6), 304-310. https://doi.org/10.1097/YPG.0b013e32833adccb

Hintsanen, M., Kivimäki, M., Hintsa, T., ... Keltikangas-Järvinen, L. (2010). A prospective cohort study of deficient maternal nurturing attitudes predicting adulthood work stress independent of adulthood hostility and depressive symptoms. Stress, 13(5), 425-434. https://doi.org/10.3109/10253891003692753

Howie, B.N., Donnelly, P., \& Marchini, J. (2009). A flexible and accurate genotype imputation method for the next generation of genome-wide association studies. PLoS Genetics, 5(6), e1000529. https://doi.org/10.1371/journal.pgen.1000529

Jenkins, J.M., McGowan, P., \& Knafo-Noam, A. (2016). Parent-offspring transaction: Mechanisms and the value of within-family designs. Hormones and Behavior. Academic Press. https://doi.org/10.1016/j.yhbeh.2015.06.018

Joshi, P.K., Fischer, K., Schraut, K.E., Campbell, H., ... Wilson, J.F. (2016). Variants near CHRNA3/5 and APOE have age- and sex-related effects on human lifespan. Nature Communications, 7, 11174. https://doi.org/10.1038/ncomms11174

Kendler, K.S. (1996). Parenting: A genetic-epidemiologic perspective. American Journal of Psychiatry, 153(1), 11-20. https://doi.org/10.1176/AJP.153.1.11

Klahr, A.M., \& Burt, S.A. (2014). Elucidating the etiology of individual differences in parenting: A meta-analysis of behavioral genetic research. Psychological Bulletin, 140(2), 544-586. https://doi.org/10.1037/a0034205

Knafo, A., \& Plomin, R. (2006). Parental discipline and affection and children's prosocial behavior: Genetic and environmental links. Journal of Personality and Social Psychology, 90(1), 147164. https://doi.org/10.1037/0022-3514.90.1.147

Kopala-Sibley, D.C., Hayden, E.P., Singh, S.M., Sheikh, H.I., ... Klein, D.N. (2016). Geneenvironment correlations in the cross-generational transmission of parenting: Grandparenting moderates the effect of child 5-HTTLPR genotype on mothers' parenting. Social Development. https://doi.org/10.1111/sode.12221

Krishna-Kumar, S., Feldman, M.W., Rehkopf, D.H., \& Tuljapurkar, S. (2015). Limitations of GCTA as a solution to the missing heritability problem. PANAS, 113(1), E61-70. https://doi.org/10.1073/pnas.1520109113

Kryski, K.R., Smith, H.J., Sheikh, H.I., Singh, S.M., \& Hayden, E.P. (2014). Evidence for evocative gene-environment correlation between child oxytocin receptor (OXTR) genotype and caregiver behavior. Personality and Individual Differences, 64, 107-110. 
https://doi.org/10.1016/j.paid.2014.02.028

Lucht, M., Barnow, S., Schroeder, W., Grabe, H.J., ... Herrmann, F. H. (2006). Negative perceived paternal parenting is associated with dopamine D2 receptor exon 8 and GABA(A) alpha 6 receptor variants: An explorative study. : Neuropsychiatric Genetics, Part B (AJMG), 141B(2), 167-172. https://doi.org/10.1002/ajmg.b.30255

Maccoby, E. E. (1980). Social development : Psychological growth and the parent-child relationship. Harcourt Brace Jovanovich.

MacDonald, K. (1992). Warmth as a developmental construct: An evolutionary analysis. Child Development, 63(4), 753-773. https://doi.org/10.1111/j.1467-8624.1992.tb01659.x

Makkonen, T., Ruoppila, I., Rönkä, T., Timonen, S., ... Österlund, K. (1981). Operation family. Child Report, No. A 34. Helsinki: Mannerheim League of Child Welfare.

Marioni, R.E., Ritchie, S.J., Joshi, P.K., Hagenaars, S.P., ... Deary, I.J. (2016). Genetic variants linked to education predict longevity. PANAS, 113(47), 13366-13371. https://doi.org/10.1073/pnas.1605334113

Mills-Koonce, W.R., Propper, C.B., Gariepy, J.-L., Blair, C., ... Cox, M.J. (2007). Bidirectional genetic and environmental influences on mother and child behavior: The family system as the unit of analyses. Development and Psychopathology, 19(4), 1073-1087. https://doi.org/10.1017/S0954579407000545

Neiderhiser, J.M., Reiss, D., Pedersen, N.L., Lichtenstein, P., ... Elthammer, O. (2004). Genetic and environmental influences on mothering of adolescents: A comparison of two samples. Developmental Psychology, 40(3), 335-351. https://doi.org/10.1037/0012-1649.40.3.335

Pener-Tessler, R., Avinun, R., Uzefovsky, F., Edelman, S., ... Knafo, A. (2013). Boys' serotonin transporter genotype affects maternal behavior through self-control: A case of evocative geneenvironment correlation. Development and Psychopathology 25, 25, 151-162. https://doi.org/10.1017/S095457941200096X

Plomin, R., DeFries, J.C., \& Loehlin, J.C. (1977). Genotype-environment interaction and correlation in the analysis of human behavior. Psychological Bulletin, 84(2), 309-322. https://doi.org/10.1037/0033-2909.84.2.309

Price, A.L., Patterson, N.J., Plenge, R.M., Weinblatt, M.E., ... Reich, D. (2006). Principal components analysis corrects for stratification in genome-wide association studies. Nature Genetics, 38(8), 904-909. https://doi.org/10.1038/ng1847

Raitakari, O.T., Juonala, M., Rönnemaa, T., Keltikangas-Järvinen, L., Räsänen, L., ... Viikari, J.S.A. (2008). Cohort profile: The cardiovascular risk in Young Finns Study. International Journal of Epidemiology, 37(6), 1220-1226. https://doi.org/10.1093/ije/dym225 
Realo, A., van der Most, P.J., Allik, J., Esko, T., Jeronimus, B.F., ... Ormel, J. (2017). SNP-based heritability estimates of common and specific variance in self- and informant-reported neuroticism scales. Journal of Personality, 85(6), 906-919. https://doi.org/10.1111/jopy.12297

Roberts, B.W., \& DelVecchio, W.F. (2000). The rank-order consistency of personality traits from childhood to old age: A quantitative review of longitudinal studies. Psychological Bulletin, 126(1), 3-25. http://dx.doi.org/10.1037/0033-2909.126.1.3

Sanson, A., Hemphill, S.A., \& Smart, D. (2004). Connections between temperament and social development: A review. Social Development, 13(1), 142-170. https://doi.org/10.1046/j.14679507.2004.00261.x

Saudino, K.J. (2005). Behavioral genetics and child temperament. Journal of Developmental and Behavioral Pediatrics, 26(3), 214-23. https://doi.org/10.1097/00004703-200506000-00010

Savelieva, K., Keltikangas-Järvinen, L., Pulkki-Råback, L., Jokela, M., ... Hintsanen, M. (2017). Intergenerational transmission of qualities of the parent-child relationship in the populationbased Young Finns Study. European Journal of Developmental Psychology, 14(4), 416-435. https://doi.org/10.1080/17405629.2016.1230057

Savelieva, K., Pulkki-Råback, L., Jokela, M., Hintsanen, M., ... Keltikangas-Järvinen, L. (2017). Intergenerational continuity in qualities of the parent-child relationship: Mediating and moderating mechanisms. Journal of Child and Family Studies, 26(8), 2191-2201. https://doi.org/10.1007/s10826-017-0729-1

Shiner, R.L., Buss, K.A., Mcclowry, S.G., Putnam, S.P., ... Zentner, M. (2012). What is temperament now? Assessing progress in temperament research on the twenty-fifth anniversary of Goldsmith et al. Child Development Perspectives, 6(4), 436-444. https://doi.org/10.1111/j.1750-8606.2012.00254.x

Smith, E.N., Chen, W., Kähönen, M., Kettunen, J., ... Murray, S.S. (2010). Longitudinal genomewide association of cardiovascular disease risk factors in the Bogalusa heart study. PLoS Genetics, 6(9), e1001094. https://doi.org/10.1371/journal.pgen.1001094

Stams, G.J.J., Juffer, F., \& van IJzendoorn, M.H. (2002). Maternal sensitivity, infant attachment, and temperament in early childhood predict adjustment in middle childhood: The case of adopted children and their biologically unrelated parents. Developmental Psychology, 38(5), 806-821. https://doi.org/10.1037//0012-1649.38.5.806

Vattikuti, S., Guo, J., \& Chow, C.C. (2012). Heritability and genetic correlations explained by common SNPs for metabolic syndrome traits. PLoS Genetics, 8(3), e1002637. https://doi.org/10.1371/journal.pgen.1002637

Visscher, P.M., Hemani, G., Vinkhuyzen, A.A.E., Chen, G.B., ... Yang, J. (2014). Statistical power 
to detect genetic (co)variance of complex traits using SNP data in unrelated samples. PLoS Genetics, 10(4), e1004269. https://doi.org/10.1371/journal.pgen.1004269

Yang, J., Lee, S. H., Goddard, M. E., \& Visscher, P. M. (2011). GCTA: A tool for genome-wide complex trait analysis. American Journal of Human Genetics, 88(1), 76-82. https://doi.org/10.1016/j.ajhg.2010.11.011

Yang, J., Lee, S.H., Wray, N.R., Goddard, M.E., \& Visscher, P.M. (2016). GCTA-GREML accounts for linkage disequilibrium when estimating genetic variance from genome-wide SNPs. PANAS, 113(32), E4579-80. https://doi.org/10.1073/pnas.1602743113 


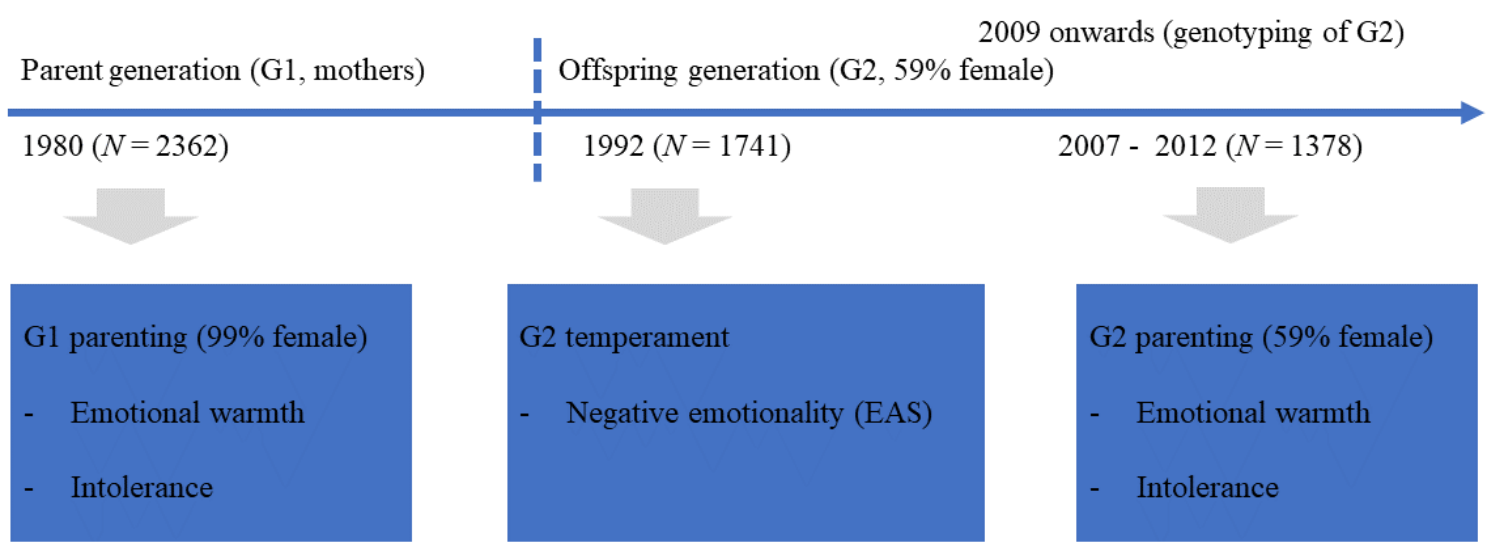

Figure 1. Study design and timeline 
Table 1. SNP-based Gene-Environment Correlation and Heritability Estimates of Parenting in Two Generations (G1, G2)

Generation 1 mothers Generation 2 participants

\begin{tabular}{|c|c|c|c|c|c|c|}
\hline Scales & $h^{2}$ & $p$ value & $N$ & $h^{2}$ & $p$ value & $N$ \\
\hline Emotional warmth & 0.088 & .243 & 2362 & 0.202 & .150 & 1377 \\
\hline Intolerance & 0.226 & .039 & 2349 & 0.000 & .500 & 1378 \\
\hline $\begin{array}{l}\text { Parenting scales } \\
\text { combined }\end{array}$ & 0.214 & .048 & 2367 & 0.062 & .381 & 1378 \\
\hline $\begin{array}{l}\text { Emotional warmth } \\
\text { corrected for } \mathrm{G} 2 \\
\text { temperament }\end{array}$ & 0.095 & .286 & 1741 & - & - & - \\
\hline $\begin{array}{l}\text { Intolerance corrected for } \\
\text { G2 temperament }\end{array}$ & 0.202 & .121 & 1733 & - & - & - \\
\hline $\begin{array}{l}\text { Parenting scales } \\
\text { combined }\end{array}$ & 0.161 & .167 & 1745 & & & \\
\hline
\end{tabular}

Notes. $h^{2}=$ SNP-based gene-environment correlation (G1), indicating the proportion of the variance children's genotype explains of the responses of their parents/heritability estimate (G2), indicating the proportion of the variance individuals' genotype explains of their own parenting; $N=$ sample size; Standard errors of $h^{2}$ were $0.125-0.171$ in G1 and 0.203-0.209 in G2. G2 temperament was assessed in 1992 by self-reports of negative emotionality. 


\section{Conflict of interest statement}

All authors declare they have no conflicts of interest and have no financial interest.

\section{Contributors}

All the authors have made a substantial contribution to conception and design, or collection, analysis and interpretation of data, writing or revising the manuscript, or providing guidance on the execution of the research. The analyses have been conducted by the first three authors. The paper has been read and approved by all the authors.

\section{Ethical approval}

Each study wave was conducted in compliance with the Helsinki Declaration and approved by local ethics committees. Written informed consent was obtained from both generations.

\section{YFS publications}

Papers that use the current dataset can be reviewed clicking this link:

http://youngfinnsstudy.utu.fi/publications.html . No other published or submitted papers have substantial overlap with the work submitted to Journal of Child Psychology and Psychiatry.

\section{Acknowledgements}

The Young Finns Study has been financially supported by the Academy of Finland: grants 258578 (M.H.), 265869 (Mind), 286284, 134309 (Eye), 126925, 121584, 124282, 129378 (Salve), 117787

(Gendi), and 41071 (Skidi); the Social Insurance Institution of Finland; Competitive State Research Financing of the Expert Responsibility area of Kuopio, Tampere and Turku University Hospitals (grant X51001); Juho Vainio Foundation; Paavo Nurmi Foundation; Finnish Foundation for Cardiovascular Research ; Finnish Cultural Foundation; Tampere Tuberculosis Foundation; Emil 
Aaltonen Foundation; Yrjö Jahnsson Foundation; Signe and Ane Gyllenberg Foundation(T.L. and L.P.-R.), Diabetes Research Foundation of Finnish Diabetes Association; and EU Horizon 2020 (grant 755320 for TAXINOMISIS). This study was further supported by a European Research Council starting grant 240994 (A.K.-N.). We want to thank Alfredo Ortega-Alonso, Kadri Haljas, and Markus Jokela for their valuable comments on a previous version of this paper. 


\section{Online Appendix}

Table S1. Inter-correlation of the Main Study Variables

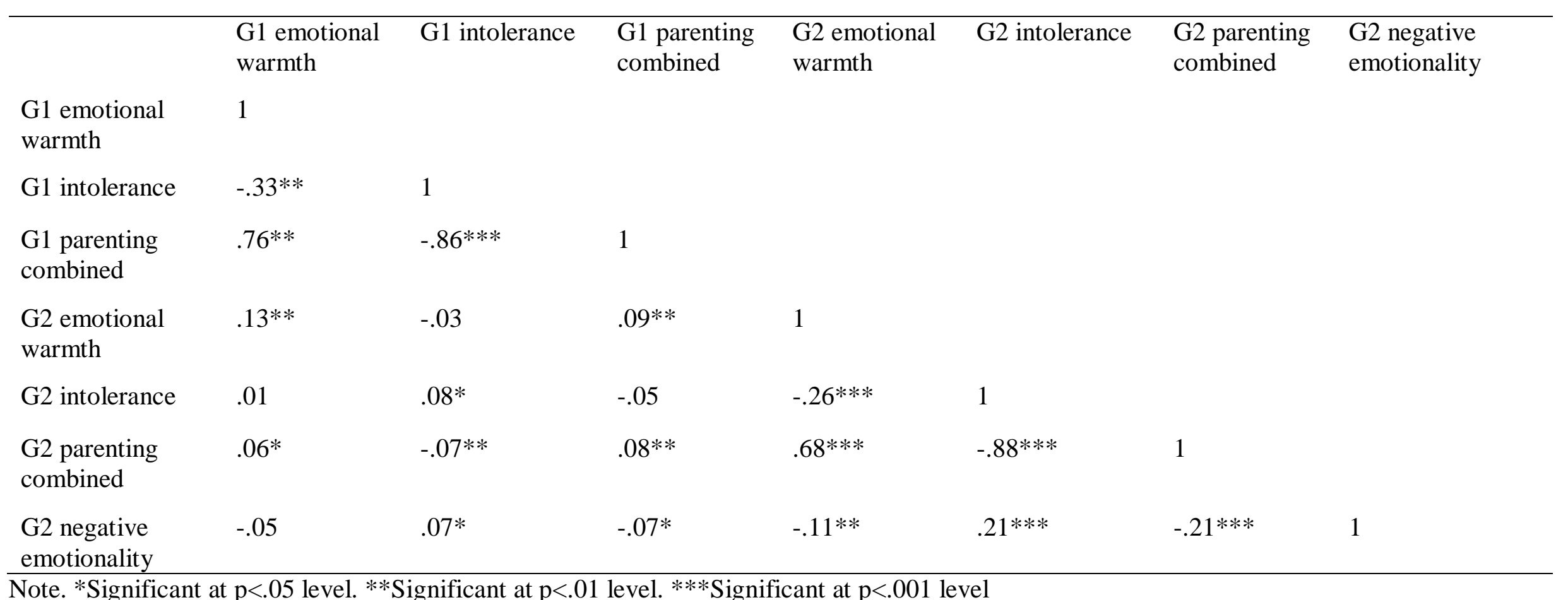

